\title{
EFFECTS OF SATURATED VAPOR PRE-STEAMING ON DRYING STRAIN IN ASIAN WHITE BIRCH: EXPERIMENTATION AND MODELLING
}

\author{
Zongying Fu ${ }^{1}$,Stavros Avramidis ${ }^{2,}$ Jingyao Zhao ${ }^{3,}$ Yingchun Cai $^{3,}$ Yongdong Zhou ${ }^{1, \text { }}$
}

\begin{abstract}
The effect of low pressure saturated vapor pre-steaming on restrained shrinkage strain, mechanosorptive creep and the distribution of moisture content was investigated during conventional drying of wood discs. Mechano-sorptive creep was furthermore modelled by artificial neural network theory with five inputs, i.e., pre-steaming and drying temperatures, wood moisture content, relative humidity and distance from the pith. Results revealed that, pre-steaming partly reduced the variation of moisture content distribution along radial direction, increased restrained shrinkage strain in heartwood and decreased in sapwood and slightly decreased the mechano-sorptive creep. The neural network model provided reasonable prediction results, namely, the coefficient of determination for training, validation and test sets greater than 0,95 .
\end{abstract}

Keywords: Artificial neural network, Betula platyphylla, mechano-sorptive creep, restrained shrinkage strain, white birch discs.

\section{INTRODUCTION}

Numerous studies have been carried out for the improvement of wood drying quality with various pretreatments, such as chemical modification, dry or wet heat treatment. The latter is exposing wood to saturated steam for a period of time just before drying begins (pre-steaming). Pre-steaming has been reported to increase dimensional stability (Fruhwald 2006) and wood permeability (Dashti et al. 2012, Ratnasingam et al. 2014), reduce moisture gradients within wood (Simpson 1976, Alexiou et al. 1990b, Avramidis and Oliveira 1993), and alleviate drying defects (Chafe 1995, Chafe and Carr 1998). Furthermore, some researchers argued that pre-steaming reduced drying time by increasing drying rate (Simpson 1975, Alexiou et al. 1990a, Ratnasingam et al. 2014), while others reported that presteaming reduced moisture content (MC) loss rate (Chafe and Ananias 1996). Avramidis and Oliveira (1993) concluded that pre-steaming had no clear influence on drying rate when hem-fir lumber was pre-steamed at $100^{\circ} \mathbf{C}$ for 5,10 , or 20 hours.

The effect of pre-steaming on shrinkage has been a critical concern. Campbell (1961) considered that relatively short periods of pre-steaming may not significantly alter shrinkage characteristics, but prolonged exposure does cause some changes. Chafe (1990) concluded that pre-steaming resulted in significant increase in shrinkage during oven-dried for 24 hours at 103. Alexiou et al. (1990a) reported

\footnotetext{
${ }^{1}$ Research Institute of Wood Industry, Chinese Academy of Forestry; Key Lab of Wood Science and Technology of State Forestry Administration, Beijing, P.R. China

${ }^{2}$ Department of Wood Science, University of British Columbia, Vancouver, BC, Canada

${ }^{3}$ College of Material Science and Engineering, Northeast Forestry University, Harbin, P.R. China

"Corresponding author: zhouyd@caf.ac.cn

Received: 10.10.2017 Accepted: 14.08.2018
} 
that pre-steaming did not affect volumetric shrinkage. Although there are some studies, albeit conflicting, about the pre-steaming effect on shrinkage, there appears to be no information in the literature about its effect on drying stresses.

It is well documented that drying stresses are the main cause of wood drying defects that greatly affect quality. Better understanding of how drying stresses evolve might allow schedule optimization and defect reduction. Rice and Youngs (1990) investigated the relationship of creep to MC change and load level by using loaded wafers and the slicing method. Some researchers measured drying stresses online in kiln drying process with stress sensors (Allegretti and Ferrari 2008, Ferrari et al. 2010). In addition, others developed rheological models to exhibit the evolution of drying stresses and deformations (Salin 1992, Wu and Milota 1995, Märtensson and Svensson 1997, Moutee et al. 2007, Salinas et al. 2015, Zhan and Avramidis 2017). In recent studies, Larsen and Ormarsson (2013), Larsen and Ormarsson (2014) reported on drying experiments and numerical simulations based on finite element modeling of the moisture-induced stress and strain, but it must make some assumptions.

A large number of comprehensive experiments are needed for determining drying stresses because wood MC, air temperature and humidity change constantly during drying process. Because of procedural difficulties, long times and high costs for this type of experiments, proper modeling becomes paramount. As a powerful tool for modeling without assumptions and knowing a priori the model structure, artificial neural networks (ANN) have been widely used in the field of wood evaluation and processing. Avramidis and Iliadis (2005a), Avramidis and Iliadis (2005b) developed ANN models to predict the thermal conductivity and water sorption isotherms of wood. Tiryaki and Aydin (2014) predicted the compression strength parallel to grain of heat-treated woods indicated that ANN modeling provided high predictive precision, and the $R^{2}$ for the testing set was obtained as $0,997 \%$. Watanabe et al. (2014) investigated the drying stress at the surface of lumber during drying using near-infrared spectroscopy combined with ANN models.

The aim of this study is to explore the effect of pre-steaming on drying strains and MC distribution in wood during drying process, to understand the controlling mechanisms and to develop an ANN model to predict mechano-sorptive creep in a non-destructive, swift and inexpensive way.

\section{MATERIALS AND METHODS}

\section{Materials preparation}

One 3-meter-length plantation white birch (Betula platyphylla) log (22 years old, average diameter of $23 \mathrm{~cm}$ ) was collected from Lesser Khingan Mountains in Heilongjiang province of China. Its initial average MC was about $80 \%$, which was determined by oven-dry method.

The log was cut into $30 \mathrm{~mm}$-thickness wood discs, and then sealed in plastic bags and stored in a freezer to prevent water loss and decay. Thirty defect-free wood discs were randomly selected and divided into three groups (10 discs each). In each group, one piece of discs was used to determine moisture content before drying experiment $\left(\mathrm{MC}_{\mathrm{i}}\right)$, three for determining target moisture content $\left(\mathrm{MC}_{\mathrm{t}}\right)$, and the remaining six were used for strain measurements. The study was replicated by selecting another thirty wood discs from the original log and repeating the above.

\section{Pre-steaming treatment and drying experiments}

Prior to drying, two of the three groups (the third was the control) were pre-steamed with steam/ air at $100 \%$ relative humidity (dry-bulb and wet-bulb temperatures were equal) at $80^{\circ} \mathrm{C}$ and saturated vapor at $100^{\circ} \mathrm{C}$ for 10 hours, respectively. The conditioning was carried out simultaneously in two identical laboratory conditioning chambers (type: GDS-100, Shanghai Scientific Instruments Yiheng Co., Ltd., Shanghai, China). After pre-steaming, three groups of specimens were dried in one chamber with the drying schedule, which is listed in Table 1. The replication experiment was conducted as the mentioned procedures. Before formal drying runs, a preliminary experiment was carried out to acquire the relationship between weight and $\mathrm{MC}$ of wood disc. Thus, the approximate MC could be determined 
immediately by weighing the wood discs, with the oven-dry method as an afterwards verification step.

Table 1: Drying schedule for Asian white birch discs.

\begin{tabular}{|ccccc|}
\hline $\begin{array}{c}\text { Moisture } \\
\text { content } \\
(\%)\end{array}$ & $\begin{array}{c}\text { Dry-bulb } \\
\text { temperature } \\
\left({ }^{(\mathrm{C})}\right.\end{array}$ & $\begin{array}{c}\text { Wet-bulb } \\
\text { temperature } \\
\left({ }^{(\mathrm{C})}\right.\end{array}$ & $\begin{array}{c}\text { Relative } \\
\text { humidity } \\
(\%)\end{array}$ & $\begin{array}{c}\text { Equilibrium } \\
\text { moisture } \\
\text { content (\%) }\end{array}$ \\
\hline$>50$ & 40 & 38 & 88 & 18.3 \\
\hline $40-35$ & 40 & 37 & 82 & 16 \\
\hline $35-30$ & 40 & 36 & 76 & 14.1 \\
\hline $30-25$ & 42 & 35 & 71 & 12.7 \\
\hline $25-20$ & 43 & 34 & 66 & 11.5 \\
\hline $20-15$ & 44 & 32 & 57 & 9.6 \\
\hline $15-10$ & 45 & 30 & 48 & 8.2 \\
$<10$ & 45 & 29 & 44 & 7.6 \\
\hline
\end{tabular}

\section{Determination of MC and drying strains}

$\mathrm{MC}_{\mathrm{i}}$ and $\mathrm{MC}_{\mathrm{t}}$ were determined from initial weight and oven-dry weight which was gotten by placing specimens in a DHG-9070A drying oven (Shanghai Scientific Instruments Yiheng Co., Ltd., Shanghai, China) at a temperature of $103 \pm 2{ }^{\circ} \mathrm{C}$ until a constant weight. The drying strains, which included shrinkage strain and mechano-sorptive creep, were determined by image analysis method (Fu et al. 2015, Fu et al. 2016a), it is a noncontact method based on the distance between two dots. A digital camera $(1628 \times 1236$ resolution) was fixed to a tripod, and kept $200 \mathrm{~mm}$ from the wood disc under evaluation. Before drying, blue dots were sprayed on the polished surface of the wood discs by oil-based pike at fixed locations (tangential distance between two dots of $20 \mathrm{~mm}$ ), as shown in Figure 1. As $\mathrm{MC}_{\mathrm{t}}$ reached to $28 \%, 20 \%$ and $12 \%$ in drying process, one wood disc randomly selected for each group was cut to smaller test specimens $(30 \times 10 \times 30 \mathrm{~mm}$, tangential $\times$ radial $\times$ longitudinal $)$ for drying strain tests, and consecutive images of the discs (including a scale-plate) were taken before and after cutting. Then, the images were imported into a software called Image $\mathbf{J}$ to measure and analyze the actual length of the two blue dots. By comparing the changes of the distance between the two dots, the strain values were obtained.
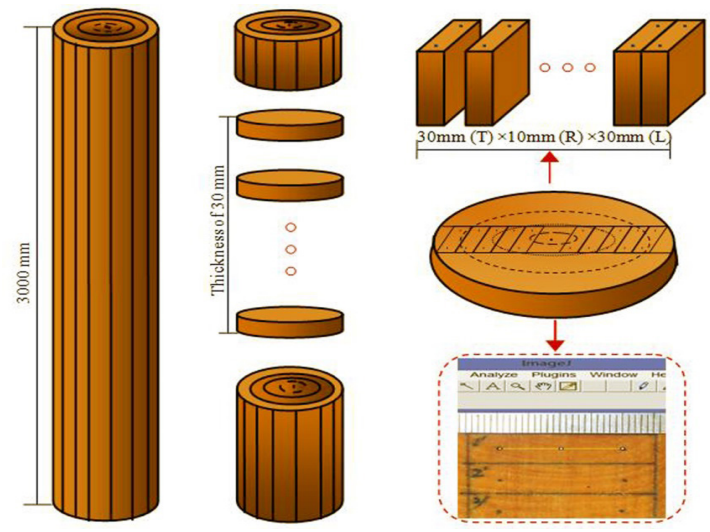

Figure 1: Cutting and testing diagram for wood specimens.

The free shrinkage strain $\left(\varepsilon_{f}\right)$, restrained shrinkage strain $\left(\varepsilon_{s}\right)$ and mechano-sorptive creep $\left(\varepsilon_{m}\right)$ were calculated by the following Equation 1, Equation 2 and Equation 3. 


$$
\begin{aligned}
& \boldsymbol{\varepsilon}_{f}=\left(L_{0}-L_{3}\right) / L_{0} \\
& \boldsymbol{\varepsilon}_{s}=\left(L_{0}-L_{1}\right) / L_{0} \\
& \boldsymbol{\varepsilon}_{m}=\left(L_{2}-L_{3}\right) / L_{0}
\end{aligned}
$$

where $L_{0}$ is the distance in mm between two dots on the strain specimens before drying, $L_{l}$ is the distance in mm between two dots on the strain specimens before cutting at each $\mathrm{MC}_{\mathrm{t}}, L_{2}$ is the distance in $\mathrm{mm}$ between two dots under stable moisture conditions, achieved by placing the strain specimens in a conditioning chamber with equilibrium moisture content equal to MC when the slice shows a split and $L_{3}$ is the distance of two dots with the strain slices soaked in water for 24 hours, steamed for 10 $\mathrm{h}$ after finishing the test for $L_{2}$, and placed in a conditioning chamber to maintain the temperature and humidity conditions in $L_{2}$.

\section{Artificial neural network modeling}

A feedforward multi-layer perception network as depicted in Figure 2 was used in this study, which comprised of an input layer, an output layer, one or more hidden layers (Avramidis and Iliadis 2005a, Avramidis and Iliadis 2005b, Avramidis and Iliadis 2006, Tiryaki and Hamzacebi 2014). The experimental results were divided into three groups at random without repetitions, namely, the training set (98 test specimens, $60 \%$ of the total), the validation set (32 test specimens, $20 \%$ of the total) and the testing set (32 test specimens, $20 \%$ of the total). To make the transfer function more effective, the input variables and output values are normalized before training the model by means of Equation 4 .

$$
X^{\prime}=\frac{X-X_{\min }}{X_{\max }-X_{\min }}
$$

where $X^{\prime}$ is the value after normalisation of vector $X$, and $X_{\max }$ and $X_{\min }$ is the maximum and minimum values of vector $X$.

Pre-steaming temperature, drying temperature, wood MC, relative humidity and distance from the pith were considered as the inputs, whereas mechano-sorptive creep was the output. The number of neurons in the hidden layer was adjusted by trial-and-error during training and validation. The optimal configuration was eight neurons in the hidden layer thus resulting in a 4-8-1 network configuration. The performance of the network was evaluated by the mean squared error (MSE), the correlation coefficient $(R)$ and the coefficient of determination $\left(R^{2}\right)$. The Levenberg-Marquardt back-propagation algorithm was considered as the training algorithm. The tangent sigmoid function (Equation 5) in the hidden layer and the linear function in the output layer were chosen as the transfer functions.

$$
\tan \operatorname{sig}(x)=\frac{2}{1+e^{-2 x}}-1
$$

where $\tan \operatorname{sig}(x)$ is the output value of the neuron; and $x$ is the input value of the neuron. 


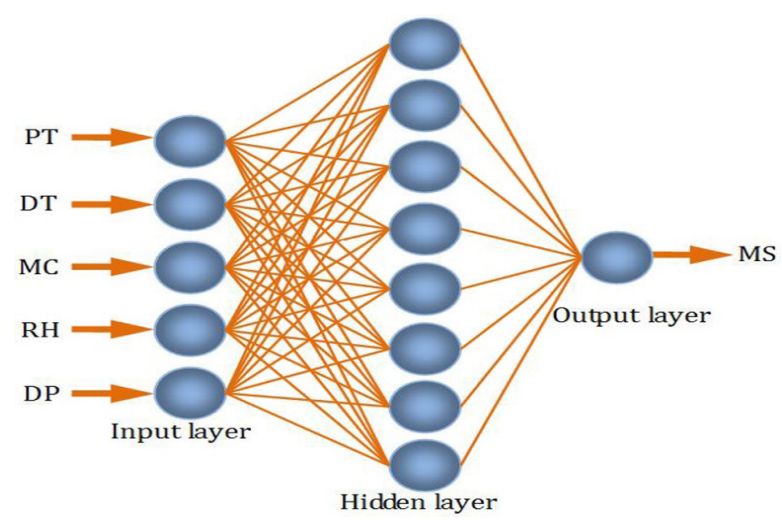

Figure 2: Configuration of the ANN model used for predicting mechano-sorptive creep: PT-presteamed temperature; DT-drying temperature; MC-moisture content; RH-relative humidity DPdistance from the pith; MS-mechano-sorptive creep.

\section{RESULTS AND DISCUSSION}

\section{Effect of pre-steaming on initial MC and MC distribution}

The variation of initial MC from the pith to bark direction and MC distribution after pre-steaming are depicted in Figure 3. There was no obvious uneven distribution of $\mathrm{MC}$ along radial direction, except the $\mathrm{MC}$ near bark was a little lower than other radial positions. The $\mathrm{MC}$ were all decreased after presteaming, the MC reduced about 7\% and 10\% for PS80 and PS100 group, respectively. Four hours of steaming in a saturated steam atmosphere caused a drop of approximately $10 \%$ for initial MC reported by Harris (1989). Moreover, the distribution of MC was more even after pre-steaming. As a conclusion, the pre-steaming can reduce the initial $\mathrm{MC}$, and also contributed to the uniform distribution of $\mathrm{MC}$ before drying.

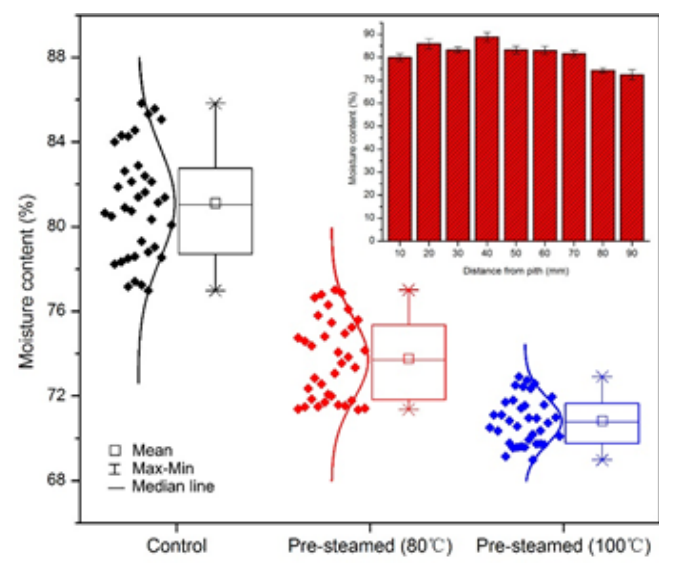

Figure 3: Initial MC along radial direction and $\mathrm{MC}$ distribution after pre-steaming.

Figure 4 illustrates the distribution of $\mathrm{MC}$ for the control and pre-steamed groups after drying. As shown, the MC distribution was more even in the specimens of the pre-steamed group with the higher treated temperature. For $\mathrm{MC}_{\mathrm{t}}$ of $28 \%$ (Figure $4 \mathrm{a}$ ), the difference of maximum and minimum values was $9 \%$ for the control, but the value was $6 \%$ and $4 \%$ for the pre-steamed at $80^{\circ} \mathrm{C}(\mathrm{PS} 80)$ and $100^{\circ} \mathrm{C}$ (PS100), respectively. When drying to $\mathrm{MC}_{\mathrm{t}}$ of $12 \%$, the value was reduced to $1 \%$ in the control and 
was less than $1 \%$ for pre-steamed groups. The results show that pre-steaming could partly reduce the variation of $\mathrm{MC}$ from pith to bark in wood discs, that is reduce the moisture gradient in radial direction, and this will result in better drying quality. This is consistent with past studies where pre-steaming decreased moisture gradients between core and shell (Alexiou et al. 1990b, Oliveira and Avramidis 1993). It is probably because pre-steaming improves the permeability and water vapor diffusivity of wood, the specific reasons need further research.
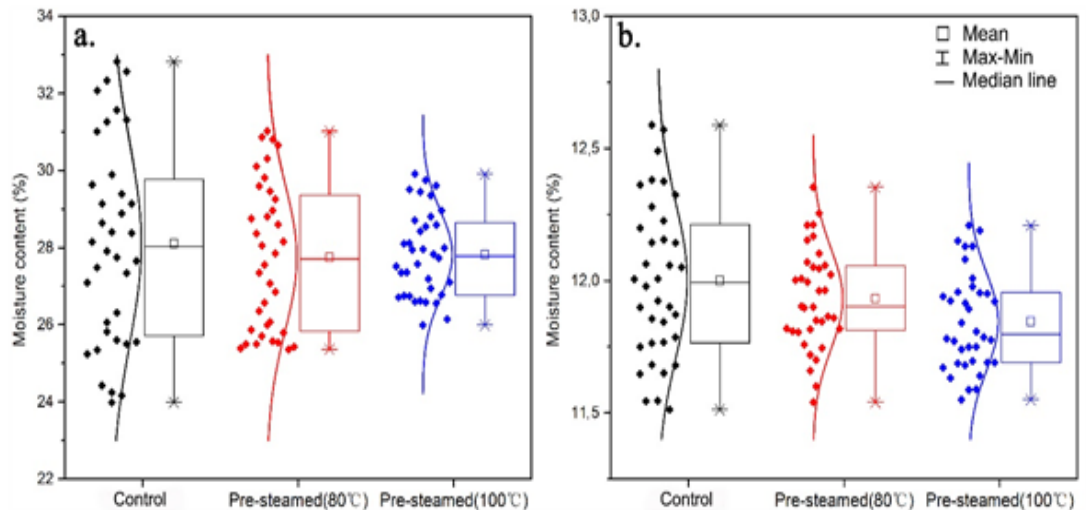

Figure 4: Box plot of MC distribution for the control and pre-steamed wood discs: (a) $\mathrm{MC}_{\mathrm{t}}$ of $28 \%$; (b) $\mathrm{MC}_{\mathrm{t}}$ of $12 \%$.

\section{Effect of pre-steaming on restrained shrinkage strain and free shrinkage strain}

During drying, shrinkage varied in different parts of the specimen due to the non-uniform distribution of $\mathrm{MC}$ and the differences in grain direction. For wood discs, the shrinkage in the tangential direction was restrained by the radial direction, and the shrinkage in lower MC parts was retrained by the higher $\mathrm{MC}$ parts (Fu et al. 2016b). Therefore, the shrinkage strain was not just induced by only the loss of MC, but also due to the restrained drying stresses. The restrained shrinkage strain at different mean $\mathrm{MC}$ was shown in Figure 5a. As this figure shows, the restrained shrinkage strain in the control was less than the pre-steamed groups at distances of 10-25 mm and 10-30 mm from the pith for $\mathrm{MC}_{t}$ of $28 \%$ and $10 \%$, respectively. However, at $40-90 \mathrm{~mm}$ distance, the restrained shrinkage in the control became greater than that in the pre-steamed groups. Thus, pre-steaming increased restrained shrinkage strain in the heartwood, but caused reduction in the sapwood. These can be interpreted as a result of changes in sapwood permeability that were adequate to overcome any weakening of the cell walls through heat effects; in the heartwood, however, extractive easily removed by saturated vapor that consequently, caused an increase in shrinkage (Chafe 1993). Figure 5b depicts the effect of pre-steaming on free shrinkage strain at mean $\mathrm{MC}_{t}$ of $28 \%$ and $12 \%$. At $\mathrm{MC}_{t}$ of $28 \%$, the free shrinkage strain in the presteamed group was lower than the control. And the free shrinkage strain in PS80 and PS100 group were closed to the restrained shrinkage strain in each corresponding group. However, at $\mathrm{MC}_{\mathrm{t}}$ of $10 \%$, the free shrinkage distinction non-obvious for each group. 

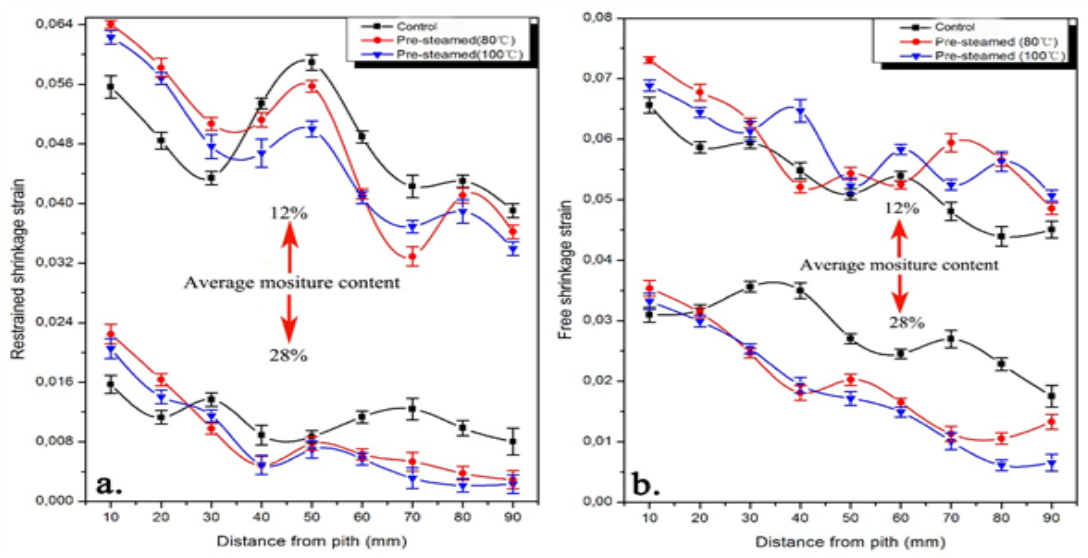

Figure 5: (a) Distribution of restrained shrinkage strain and (b) free shrinkage strain for the control and pre-steamed wood discs at $\mathrm{MC}_{\mathrm{t}}$ of $28 \%$ and $12 \%$ plotted against by the distance from the pith.

\section{Effect of pre-steaming on mechano-sorptive creep}

Figure 6 illustrates the distribution for the mechano-sorptive creep obtained in the control and PS80 and PS100. As seen, the mechano-sorptive creep near the pith showed no noticeable changes for different groups and $\mathrm{MC}$. For $\mathrm{MC}_{\mathrm{t}}$ of $28 \%$, the tensile mechano-sorptive creep was present at 20$50 \mathrm{~mm}$ from the pith, and the creep value in the control was slightly higher than that in the PS80 and PS100 groups. At $\mathrm{MC}_{\mathrm{t}}$ of $12 \%$, the higher creep value was still observed in the control for each radial position except to the distance of $10 \mathrm{~mm}$. Thus, the mechano-sorptive creep was slightly decreased with pre-steaming. In addition, the changes of mechano-sorptive creep in PS80 were similar to PS100 group, especially for $\mathrm{MC}_{t}$ of $28 \%$, which showed that the pre-steamed temperature had little effect on mechano-sorptive creep.

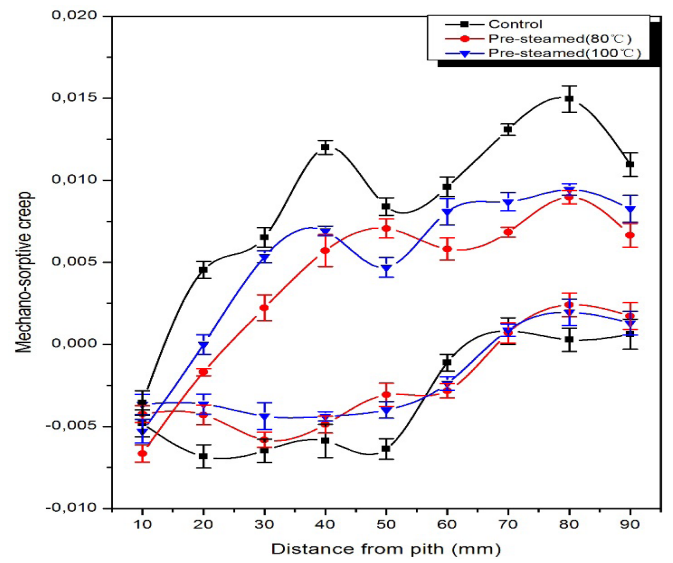

Figure 6: Distribution mechano-sorptive creep for the control and pre-steamed wood discs at $\mathrm{MC}_{\mathrm{t}}$ of $28 \%$ and $12 \%$ plotted against by the distance from the pith.

\section{Prediction of mechano-sorptive creep by the ANN model}

As depicted in Figure 7, the MSE values in the training, validation and test sets were all close to the goal line. The MSE decreased with increased number of iterations, and it achieved the best validation performance of $1,437 \mathrm{e}-06$ at epoch 10 . 
Figure 8 illustrates the comparison of experimental and predicted values for mechano-sorptive creep at $\mathrm{MC}_{\mathrm{t}}$ of $20 \%$. It appears that the predicted values are very close to the experimental ones for all groups, especially in the PS100. This situation proves the reliability of the developed ANN model and gives a good method for predicting other drying strains by using ANN models.

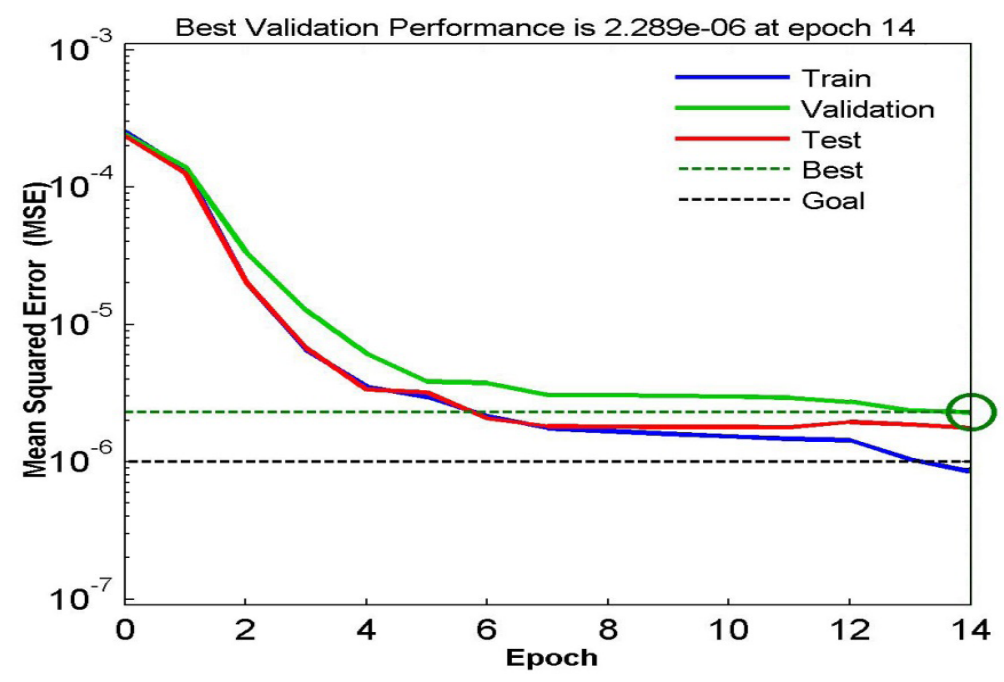

Figure 7: Plot of mean squared error of training, validation and test changes with iteration.

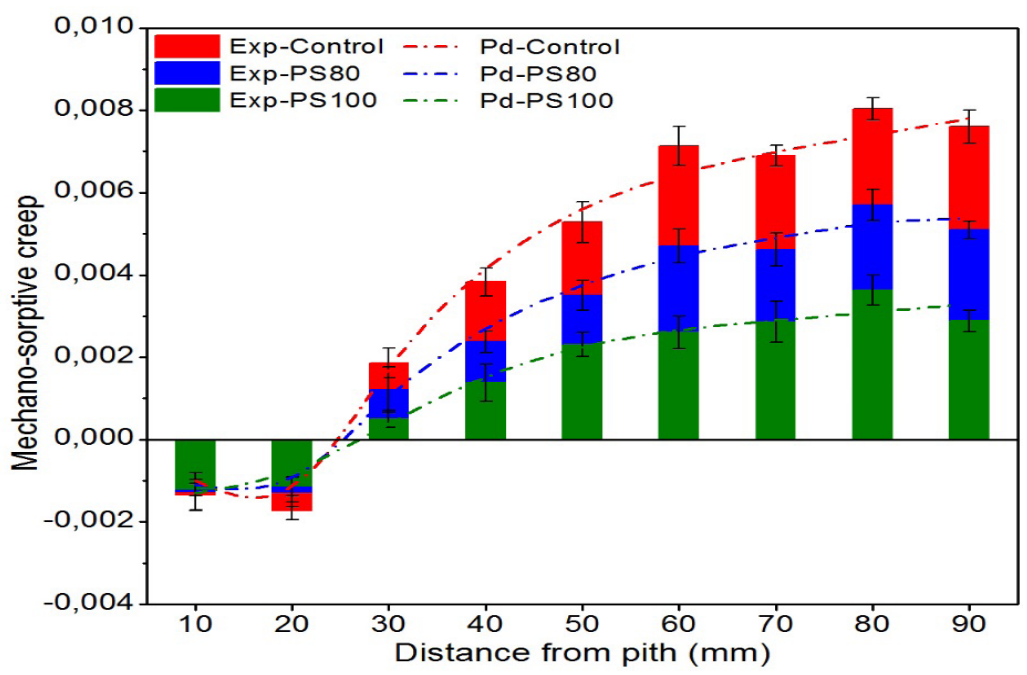

Figure 8: Prediction of mechano-sorptive creep at $\mathrm{MC}_{\mathrm{t}}$ of $20 \%$ by $\mathrm{ANN}$ : comparison of experimental (Exp) and predicted (Pd) value. PS80 indicates pre-steamed at $80^{\circ} \mathrm{C}$; PS100 indicates pre-steamed at $100^{\circ} \mathrm{C}$

The regression fit between the experimental and predicted values for the training (Figure 9a), validation (Figure 9b) and test set (Figure 9c), in conjunction with their correlation coefficients $(R)$ and regression equations are presented in Figure 9. There are significant correlations between experimental and predicted values in all date sets. The $R$-values for training, validation and test sets are 0,$979 ; 0,975$ and 0,968 respectively. Furthermore, the $R^{2}$ values are greater than 0,95 in the three data sets, indicating 
that the network model is capable to explain more than $95 \%$ of the experimental values. From past studies that used ANNs to predict wood mechanical properties, Esteban et al. (2009) determined the modulus of elasticity, achieving 75\% success. Tiryaki and Aydin (2014) reported $R^{2}$ values were greater than 0,99 for all data sets in predicting compression strength of heat-treated woods.
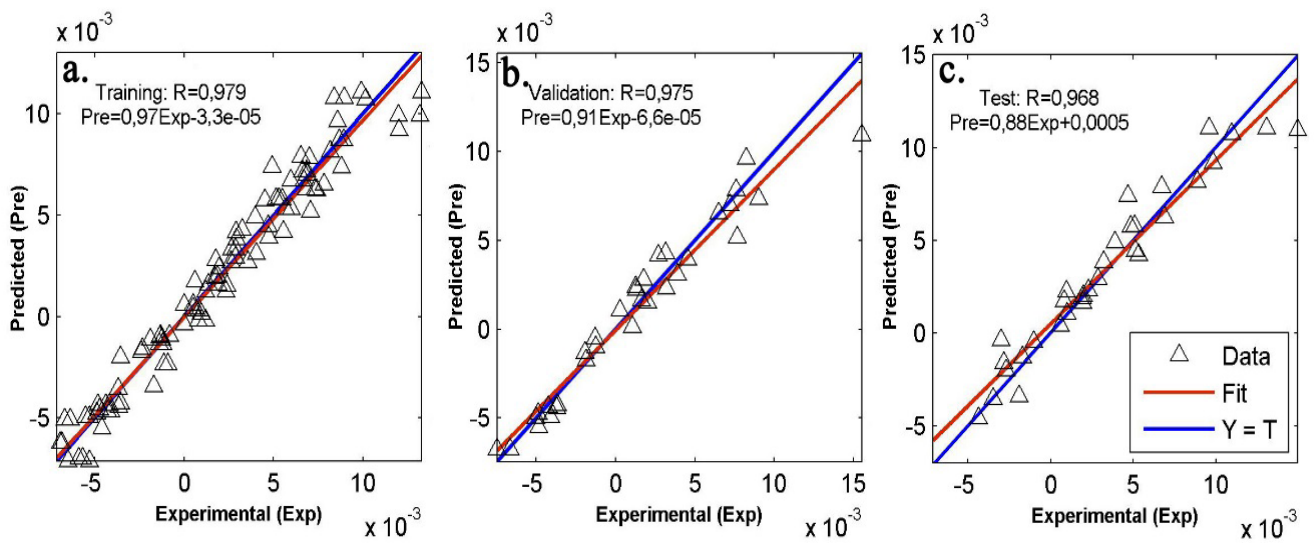

Figure 9: Relationship between experimental and predicted value for training (a), validation (b) and test (c).

\section{CONCLUSIONS}

The effect of saturated vapor pre-steaming on restrained shrinkage strain, mechano-sorptive creep and $\mathrm{MC}$ distribution in white birch discs was investigated in this study. And the mechano-sorptive creep was predicted by a developed feedforward multi-layer perception neural network.

In summary, the pre-steaming could partly reduce the variation of $\mathrm{MC}$ from the pith to bark in wood discs; the pre-steaming caused increase in heartwood but reduction in sapwood for restrained shrinkage strain. Also, the pre-steaming slightly eased mechano-sorptive creep. The distribution of $\mathrm{MC}$ along radial in wood discs was uniform after pre-steaming. When the experimental values were compared with predicted ones obtained by the neural network model, the $R^{2}$ values were greater than 0,95 for all data sets, showing that ANN can be used successfully for prediction of mechano-sorptive creep of pre-steaming wood. The use of this method is of major importance for reducing time and cost associated to experimentation, and at the same time, it opens up a new field for the prediction of drying strains by neural network modelling.

\section{ACKNOWLEDGEMENTS}

This work was supported by the National Forestry Industry Research Special Funds for Public Welfare Projects from State Forestry Administration of China (No. 201404502). 


\section{REFERENCES}

Alexiou, P.N.; Wilkins, A.P.; Hartley, J. 1990a. Effect of pre-steaming on drying rate, wood anatomy and shrinkage of regrowth Eucalyptus pilularis Sm. Wood Science and Technology 24(1): 103-110.

Alexiou, P.N.; Marchant, J.F.; Groves, K.W. 1990b. Effect of pre-steaming on moisture gradients, drying stresses and sets, and face checking in regrowth Eucalyptus pilularis Sm. Wood Science and Technology 24(2): 201-209.

Allegretti, O.; Ferrari, S. 2008. A Sensor for direct measurement of internal stress in wood during drying: Experimental tests toward industrial application. Drying Technology 26(9): 1150-1154.

Avramidis, S.; Iliadis, L. 2005a. Predicting wood thermal conductivity using artificial neural networks. Wood and Fiber Science 37(4): 682-690.

Avramidis, S.; Iliadis, L. 2005b. Wood-water sorption isotherm prediction with artificial neural networks: a preliminary study. Holzforschung 59(3): 336-341.

Avramidis, S.; Iliadis, L.; Mansfield, S.D. 2006. Wood dielectric loss factor prediction with artificial neural networks. Wood Science and Technology 40(7): 563-574.

Avramidis, S.; Oliveira, L. 1993. Influence of pre-steaming on kiln-drying of thick hem-fir lumber. Forest Products Journal 43(11): 7-12.

Campbell, G.S. 1961. The value of presteaming for drying some collapse susceptible eucalypts. Forest Products Journal 9: 343-347.

Chafe, S.C. 1990. Effect of brief presteaming on shrinkage, collapse and other wood-water relationships in Eucalyptus regnans F. Muell. Wood Science and Technology 24(4): 311-326.

Chafe, S.C. 1993. The effect of boiling on shrinkage, collapse and other wood-water properties in core segments of Eucalyptus regnans E. Muell. Wood Science and Technology 27(3): 205-217.

Chafe, S.C. 1995. Preheating and continuous and intermittent drying in boards of Eucalyptus regnans F. Muell. I. Effect on internal checking, shrinkage and collapse. Holzforschung 49(3): 227-233.

Chafe, S.C.; Ananias, R.A. 1996. Effect of pre-steaming on moisture loss and internal checking in high-temperature-dried boards of Eucalyptus globulus and Eucalyptus regnans. Journal of the Institute of Wood Science 14(2): 72-77.

Chafe, S.C.; Carr, J.M. 1998. Effect of preheating on internal checking in boards of different dimension and grain orientation in Eucalyptus regnans. Holz als Roh-und Werkstoff 56(1): 15-23.

Dashti, H.; Tarmian, A.; Faezipour, M.; Hedjazi, S.; Shahverdi, M. 2012. Effect of presteaming on mass transfer properties of fir wood (Abies albal.); a gymnosperm species with torus margo pit membrane. BioResources 7(2): 1907-1018.

Esteban, L.G.; Fernandez, F.G.; Palacios, P.D. 2009. MOE prediction in Abies pinsapo Boiss. timber: Application of an artificial neural network using non-destructive testing. Computers \& Structures 87(21-22): 1360-1365.

Ferrari, S.; Pearson, H.; Allegretti, O.; Gabbitas, B. 2010. Measurement of internal stress in Radiata pine sapwood during drying using an improved online sensor. Holzforschung 64(6): 781-789.

Fu, Z.Y.; Zhao, J.Y.; Sun, X.M.; Cai, Y.C. 2015. The variation of tangential rheological properties caused by shrinkage anisotropy and moisture content gradient in white birch disks. Holzforschung 69(5): 573-579.

Fu, Z.Y.; Zhao, J.Y.; Lv, Y.Y.; Huan, S.Q.; Cai, Y.C. 2016a. Stress characteristics and stress 
reversal mechanism of white birch (Betula platyphylla) disks under different drying conditions. Maderas-Ciencia y tecnología 18(2): 361-372.

Fu, Z.Y.; Zhao, J.Y.; Yang, Y.L.; Cai, Y.C. 2016b. Variation of drying strains between tangential and radial directions in Asian White Birch. Forests 7 (3): 59-59.

Fruhwald, E. 2006. Improvement of shape stability by high-temperature treatment of Norway spruce Effects of drying at $120{ }^{\circ} \mathrm{C}$ with and without restraint on twist. Holz als Roh- und Werkstoff 64(1): 24-29.

Harris, R.A.; Schroeder, J.G.; Addis, S.C. 1989. Steaming of red oak prior to kiln-drying: effects on moisture movement. Forest Products Journal 39(11/12): 70-72.

Larsen, F.; Ormarsson, S. 2013. Numerical and experimental study of moisture-induced stress and strain field developments in timber logs. Wood Science and Technology 47(4): 837-852.

Larsen, F.; Ormarsson, S. 2014. Experimental and finite element study of the effect of temperature and moisture on the tangential tensile strength and fracture behavior in timber logs. Holzforschung 68(1): 133-140.

Märtensson, A.; Svensson, S. 1997. Stress-strain relationship of drying wood Part 1: Development of a constitutive model. Holzforschung 51(5): 472-478.

Moutee, M.; Fortin, Y.; Fafard, M. 2007. A global rheological model of wood cantilever as applied to wood drying. Wood Science and Technology 41(3): 209-234

Oliveira, L.C.; Avramidis, S. 1993. Effect of presteaming on shrinkage and moisture content distribution of 4" by 4" Hemfir lumber. Western Dry Kiln Association Meeting 44"

Ratnasingam, J.; Grohmann, R.; Scholz, F. 2014. Effect of pre-steaming on the drying quality of Rubberwood. European Journal of Wood and Wood Products 72(1): 135-137.

Rice, R.W.; Youngs, R.L. 1990. The mechanism and development of creep during drying of red oak. Holz als Roh- und Werkstoff 48(2): 73-79.

Salin, J.G. 1992. Numerical predictions of checking during timber drying and a new mechanosorptive model. Holz als Roh- und Werkstoff 50(5): 195-200.

Salinas, C.; Chavez, C.; Ananias, R.A.; Elustondo, D. 2015. Unidimensional simulation of drying stress in radiata pine wood. Drying Technology 33(8): 8996-1005.

Simpson, W.T. 1975. Effect of steaming on the drying rate of several species of wood. Wood Science 7: 247-255.

Simpson, W.T. 1976. Effect of pre-steaming on moisture gradient of northern red oak during drying. Wood Science 8: 272-276.

Tiryaki, S.; Aydin, A. 2014. An artificial neural network model for predicting compression strength of heat treated woods and comparison with a multiple linear regression model. Construction and Building Materials 62: 102-108.

Tiryaki, S.; Hamzacebi, C. 2014. Predicting modulus of rupture (MOR) and modulus of elasticity (MOE) of heat treated woods by artificial neural networks. Measurement 49: 266-274.

Watanabe, K.; Kobayashi, I.; Matsushita, Y.; Saito, S.; Kuroda, N.; Noshiro, S. 2014. Application of near-infrared spectroscopy for evaluation of drying stress on lumber surface: A comparison of artificial neural networks and partial least squares regression. Drying Technology 32(5): 590-596.

Wu, Q.; Milota, M.R. 1995. Rheological behavior of Douglas-fir perpendicular to the grain at elevated temperatures. Wood and Fiber Science 27(3): 285-295. 
Zhan, J.F.; Avramidis, S. 2017. Impact of conventional drying and thermal post-treatment on the residual stresses and shape deformations of larch lumber. Drying Technology 35(1):15-24. 